INTERNATIONAL DESIGN CONFERENCE - DESIGN 2020

https://doi.org/10.1017/dsd.2020.40

\title{
PARTITIONING TYPES IN PRODUCT MODULARISATION
}

\author{
J. Pakkanen $\bowtie$, T. Lehtonen and T. Juuti \\ Tampere University, Finland \\ $\bigotimes$ jarkko.pakkanen@tuni.fi
}

\begin{abstract}
Alternative ways to divide the product into modules, partitioning types, have been identified. The research material consists of the modularisation exercise at the university. Students modularised LEGO wheel loaders for product configuration. We began to see certain basic principles for partitioning the product into modules. From these, we compiled a collection of partitioning types. Similarities between the identified partitioning types and the literature exists. Future research is concerned with whether identified partitioning types would also support modularisation in industrial projects.
\end{abstract}

Keywords: modularisation, product structure, product architecture, product families, product platform

\section{Introduction}

Demand for customisation is one of the megatrends (Deloitte Consulting GmbH, 2017). For example, 3D printing has evolved to be consumer friendly, enabling manufacturing personalised products even at home. The mass-producing companies of standard products have to become more agile along with the customisation trend. Capability to respond to rapidly changing demands is also required by traditional industry in sectors such as the manufacturing industry, where production volumes may be small and products may be large, complex and expensive. The supply chain of unique products places a heavy burden on companies. This is due, for example, to the need for a nearly identical yet different product every time. Development of capabilities to respond to customisation trend requires methodological design support and tools.

According to Andreasen's (2011) definition, the aim of modularisation is first of all to enable modifying the product from the customer's point of view so that there is similarity between the alternative building blocks, typically called module variants, and secondly to reduce complexity in business operations. $\mathrm{He}$ adds that modularisation includes designing modular product architecture and modules. In a modular product architecture, interactions between modules happen through clearly defined interfaces (Fujimoto, 2007). When designing a modular architecture, space reservations for modules, for example, must be taken into account (Förg et al., 2014). Different products can be made effectively of the product family based on the modular architecture (Harlou, 2006). This is based on identifying product customisation requirements already within the product family development phase. Customisation requirements reflect the expectations of an important market segment for the company about what kind of product options customers are expecting. These requirements have to be taken into account when considering the partitioning logic of the modular product (Pakkanen et al., 2016). Partitioning logic describes the reasons why the product range should be divided in a certain way into a set of modules (Pakkanen et al., 2019). 
The purpose of this paper is to identify alternative partitioning types to support dividing a product into modules. Our long-term objective is also to study the characteristics of these types to support finding beneficial module structure in different industrial modularisation projects. Section 2 considers the paper's goals in more detail. Section 3 presents the methodology used to study the topic. Section 4 presents results and Section 5 concludes the paper.

\section{Aim}

Even though modularisation has been studied for decades (Salvador, 2007), few modularisation projects succeed for the first time. One reason for this is the difficulty of modular product architecture design. It is easier to design a working product than a working and efficiently configurable product.

In modularisation research, the partitioning logic of the modular product portfolio is often based on function-based thinking (Kong et al., 2009; Lehtonen, 2007; Pahl and Beitz, 2013; Ulrich and Eppinger, 2008; Zacharias and Yassine, 2008). Some modularisation methods take a more holistic approach considering life cycle stages when designing module division (Krause and Eilmus, 2011; Pakkanen, 2015; Umeda et al., 2000), but when examining the publications, function-based modularisation is probably the most suggested starting point. In function-based approaches, the main idea is to define the functional structure of product variety based on the overall function and consider solution principles for each function in their own modules. The purpose of this research is to study what other alternative partitioning types than functional partitioning can be identified (research question 1). The aim is also to examine how the descriptions of identified partitioning types as a design guideline affect the quality of the result in modularisation projects (research question 2). This topic is being studied to increase knowledge about modularisation of different products in different business environments.

\section{Methodology}

Figure 1 presents the constructive research method including the main tasks and their relations. Our aim is to identify partitioning types to support module partitioning. At the beginning of the study, we increase our understanding of the module partitioning by reviewing modularisation publications and analyse experiences from modularisation projects. We will then discuss how to characterise the partitioning types. This is followed by a description of the partitioning types based on the literature observations and teaching experiments. In the research described in this paper, descriptions of partitioning types are tested solely in a university course of modularisation. After testing, it is analysed how the descriptions of partitioning types as design guidelines helped the students in the modularisation task. We also discuss whether these findings could be generalised and utilised in the industry and what impact they might have.

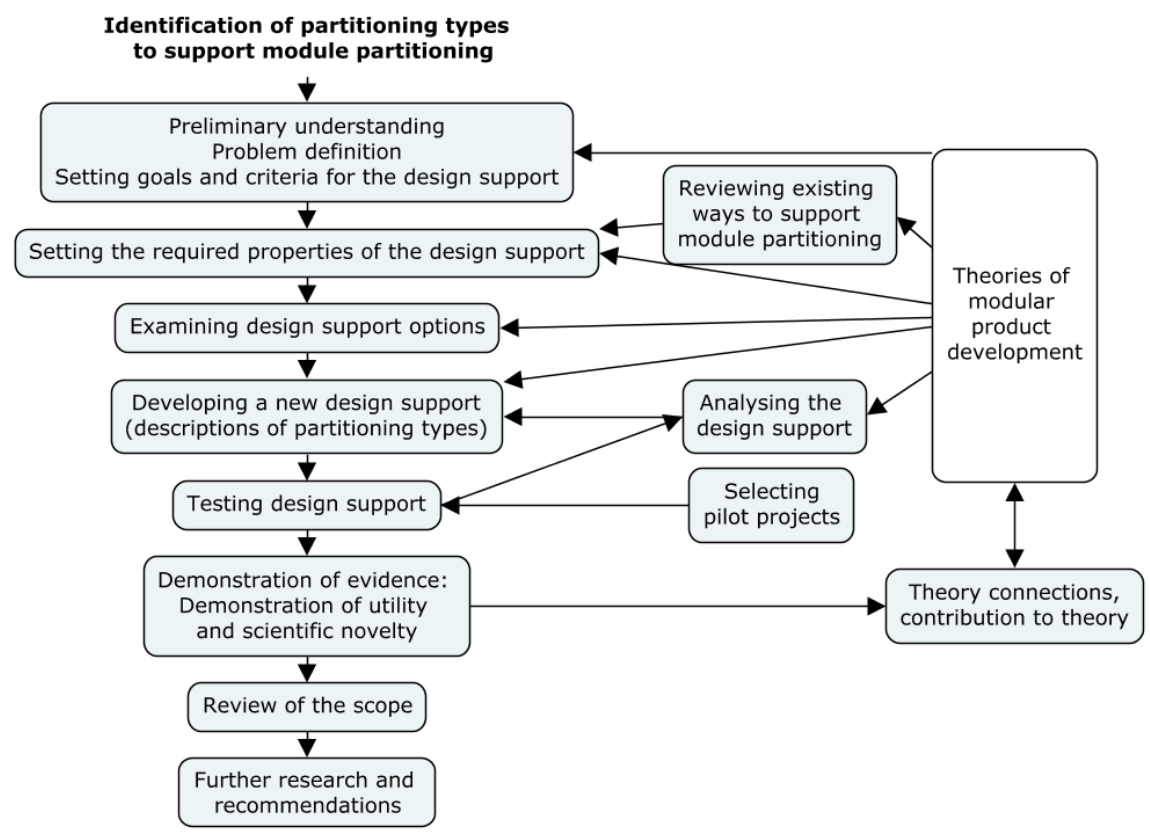

Figure 1. Research methodology 


\subsection{Literature review on partitioning products into modules}

\subsubsection{Big and small building blocks}

Building block system (Baukastensystem in German) is proposed by Borowski (1961). He studied ways to divide products into elements and discussed that the building blocks can be big or small compared to whole product. Examples of big building blocks compared to the product size can be seen in companies that manufacture heavy investment goods. A modular diesel locomotive was made at Valmet (later Transtech) rolling stock factory in Finland in 1982-92 (Juuti et al., 2019; Lehtonen, 2007). The modularity of the train was mainly designed in terms of assembly, serviceability, and not variability. A similar structure including rather large modules can also be seen on the Siemens Vectron (Siemens, 2019), Alstom Prima II locomotives (Alstom, 2008) and 2M62 diesel trains (Caterpillar, 2015). In the Transtech case study, it was noticed that even though there was not a large number of modules, each new customer requirement led to a new module and the commonality between versions remained small. Compared to big building blocks, small building blocks give flexibility. This means that there is typically a large number of modules and interfaces. Such partitioning is most easily created by applying, for example, formal modularisation methods, such as Quality Function Deployment (Hauser and Clausing, 1988) and matrix tool applications such as Design Structure Matrix (Steward, 1981). This is because these tools guide users to break dependencies between elements for example because of customer requirements. In the industry, using the small building block principle can be seen, for example, in mechatronic devices such as flexible manufacturing systems, where even a small part may be a module (Lehtonen et al., 2011).

\subsubsection{Universal chassis}

Another way of partitioning the product is related to the late variation of the product in the supply chain. Maintaining majority of a product as a standard product as long as possible may bring benefits in production. This is because then the processes can be also standardised far and complexity of manufacturing process decreases (Lee and Tang, 1997). Final product configuration would be done in the later steps of the production or even after the production. Erixon (1998) discusses that allocating variations to only one or few parts and keeping the product generic as long as possible can help in reducing inventory and thus the overall costs. Sanchez (1999) discusses that "universal chassis" including all the common components used in different variants enable mass production benefits. Use of universal chassis may reduce variety of parts that must be inventoried and handled in assembly according to him. He also explains that the late point differentiation may also reduce the costs of distributing product variations.

Because this kind of big common element is a large standardised section of the modular product it may account for the majority of the product cost in cases if it includes many functionalities and is not just "backbone" for the equipment. Therefore, it would make sense to keep the number of alternative universal chassis to a minimum. Analytical methods, such as commonality indices, have been developed to help identify existing product similarity and identify the elements that have the greatest impact on commonality (Martin and Ishii, 2002; Nomaguchi et al., 2012).

\subsubsection{Product platform}

The product platform can be defined, for example, as an entity that is reused in all variants of the product family (Kristjansson et al., 2004). Reusable entities can be considered as platforms or standard elements. There are many industry examples from product platform research. Sony Walkman is a popular example of a product platform type of partitioning (Sanderson and Uzumeri, 1995). This type of partitioning can also be seen in the smart phone processor system (Juuti, 2008). Platform-thinking has also been applied in the automotive industry. The Volkswagen Group's Modular Transversal Toolkit (Modularer Querbaukasten (MQB) in German) platform is perhaps one of the best-known solutions (Winterkorn and Pötsch, 2012). The Volkswagen Group's cars share components, design principles, and the assembly line features. If platform is considered as a standardised basic element that fulfil several essential basic functions of the product, these functions can be realised similarly and with the same quality in every variant. 
Thus, if we compare partitioning based on product platform to previously presented universal chassis and late point differentiation, universals chassis considers more about the extensivity of standardisation, not functions. Universal chassis is not necessarily considering the essential basic functions. Based on the approach by Volkswagen, the modules that are attached to the platform have little effect on product performance. Thus, the product platform is responsible for a major part of basic functionalities and the overall product performance.

\subsubsection{Frames of machine and plant units}

Borowski (1961) discusses about non-building blocks (nein-Baukasten). Such elements incorporate other elements through interfaces and do not contain smaller or variable options. Examples of using non-building blocks can be found in industry in, for example, frames of machine and plant units. Jacobs Engineering Group manufactured industrial plants whose structures consisted of large steel structural frameworks with plant technology installed. Business was later sold to Worley and because of several business changes; the material is unfortunately no longer available online. In one of their publicly reported projects (when the company was Jacobs Engineering), the average industrial plant module weighed 12 tonnes, contained about $90 \mathrm{~m}$ of pipeline, included one major equipment and 8-9 other instruments. The reported benefits of such a frame structure were primarily related to costs. This kind of module partitioning supported early freeze on the design cycle and minimising costs from incorporating late design changes. It was stated that the modularisation mitigated labor shortage by moving 65 percent of craft hours offsite to a known workforce. Also, it was explained that craft productivity improved by 50 percent.

\subsubsection{Function-based elements}

Function-based engineering design has been discussed in well-known books on product development (Pahl and Beitz, 2013; Ulrich and Eppinger, 2008). In function-based partitioning, the product is divided into modules based on the function structure. The structure of the product can be mainly such that each core function has its own module. Pahl and Beitz (2013) suggest that the definition of a function structure begins with the identification of the overall function, which is subdivided into basic, auxiliary, special, adaptive, and customer-specific functions. In a modular system, each function has its own module of the same type, but they also recognise that it is often cheaper to combine several functions into one complex function. Also, the same module can include both basic and adaptive functions from production reasons. Ulrich and Eppinger (2008) discuss that the most modular architecture is that each functional element has its own physical element (parts, components and subassemblies) and there are well defined interfaces between the elements.

\subsection{Teaching assignment related to the module partitioning}

The inspiration for writing this paper are teaching experiments in a university course focused on modularisation. Students' task is to modularise the LEGO 42030 Remote-Controlled Volvo L350F Wheel Loader shown in Figure 2. In the Modularisation Challenge (MC) assignment, a group of teachers (authors of this paper) held the role of the market and master-level student groups acted as the wheel loader suppliers. Each group consisted 4-5 students and the assignment was the same for all groups.

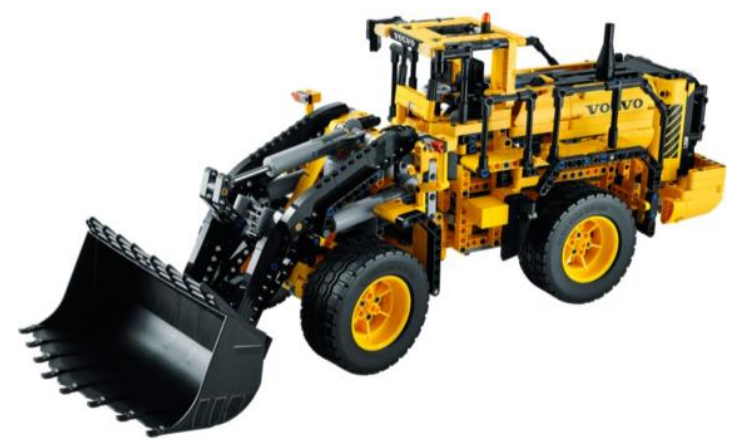

Figure 2. LEGO 42030 Remote-Controlled Volvo L350F Wheel Loader (LEGO, 2019) 
The student groups could choose from a list of variants which variation to pursue in the modularisation. Certain variations were more challenging to implement, but enabling them allowed for better grades in the assignment evaluation. Variety requests were related to boom and bucket solutions, front carriage, and rear carriage structures and power line and steering systems. The wheel loader had to be configurable without the need to rebuild the entire product when a customer orders a particular variant of the possible variants designed by each group. An additional motivation for modularisation was the five-minute time limit in the assembly of the ordered variant based on pre-designed and pre-assembled modules. Teachers asked the groups to consider market wishes and that performance such as handling of remotely controlled wheel loader should not suffer, number of items would not increase too much, and the external dimensions should remain similar to standard wheel loader. Below are the main steps of the MC:

- Studying the business and customer requirements

- Assembling the basic model (getting to know the technology)

- Modular architecture design based on the pursued variety

- Design and assembly of module prototypes

- Development and finishing work of the wheel loader

- Final event (assembly of specific customer variant and test drive)

Student groups first built the wheel loader according to the original instructions. Although LEGOs are generally thought to be modular, the loader's assembly quickly revealed that the original architecture was very integral. Components interacted in complex and overlapping ways just as, for example, Fujimoto (2007) has described the integral architecture. The standard LEGO wheel loader did not include clearly defined interfaces and module partitioning that could be used in designing other module variants requested by customers. Thus, the student teams had to modify the structure of the product more easily configurable. In addition to the parts included in the standard wheel loader, students had extra LEGO parts available for use in modularisation.

The exercise was organised for the first time in 2017. It was a voluntary way to complete the course. Four groups (4-5 people per group) participated in the first MC. In 2018, MC was compulsory for everyone and there was a total of 10 groups (4-5 people per group). Thus, during these years, 14 different designs of modular wheel loaders were created in our university course for master students. Students were required to document the structure of their modular machine separately. In the documents, they described their choices, explained the most important interfaces, outlined the variation requirements their machine is capable to fulfil and which module variants they had designed and built.

Based on the literature discussed in Section 3.1 and the teaching assignment presented in this section, the authors (teachers in MC) begun to see certain repeated principles and patterns according to which the wheel loaders were partitioned into modules despite every loader was different in detail. These are presented in the next section.

\section{Results}

This section first introduces the identified partitioning types (design support in Figure 1) based on the literature and teaching experiments discussed in the previous section. Then, the effects of the identified partitioning types as a support for modularisation in another teaching assignment are discussed.

\subsection{Identified partitioning types}

Figure 3 presents an illustrative summary of the partitioning types identified by the authors based on the 14 modularised LEGO wheel loaders and their documentation made by the students and modularisation literature. This figure and the explanations in this section are our answer to research question 1 . The authors acted as teachers in the modularisation assignment explained in Section 3.2. The following partitioning types were identified: big building blocks (BBS), small building blocks (SBS), big common element (BCE), multifunctional core element (MCE), frame-like-base element (FBE) and function-based elements (FE). It is noteworthy that in the MC assignment of 2017 and 2018, the use of FBE and FE partitioning type could not be identified in the modular wheel loaders. However, FBE and FE were included in the summary because there is clear evidence in the literature on the use of this type of partitioning in other products. The properties of these partitioning types are described in more detail below. 


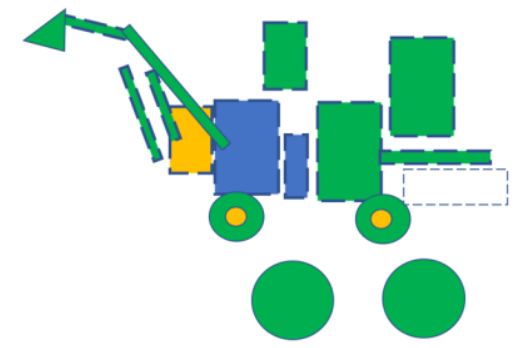

Big building blocks (BBB)

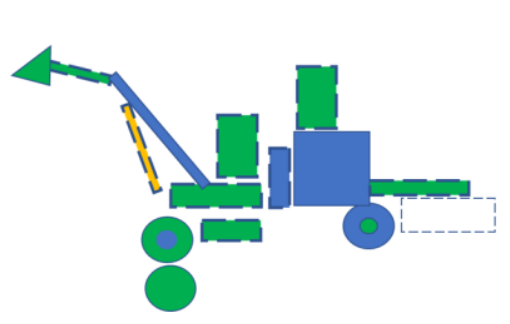

Multifunctional core element (MCE)

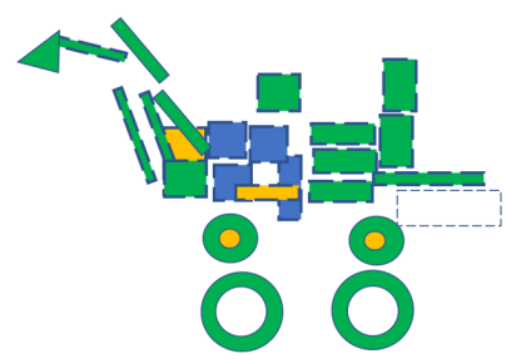

Small building blocks (SBB)

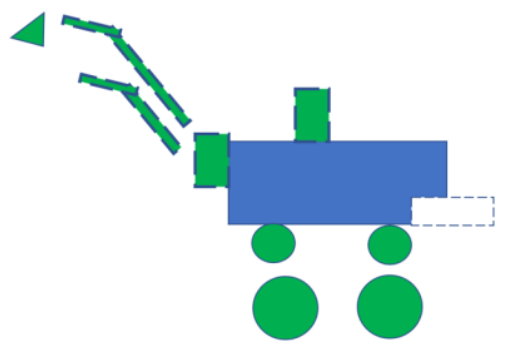

Big common element (BCE)

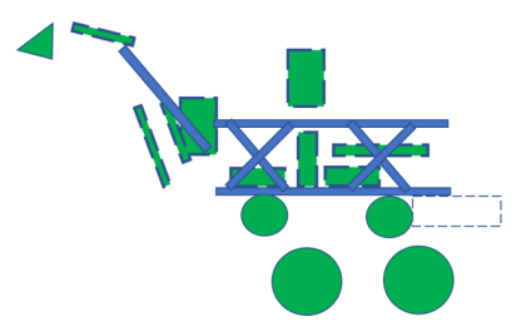

Frame-like base element (FBE)

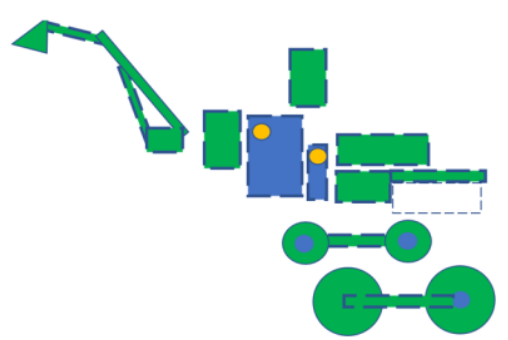

Function-based elements (FE)

Figure 3. Rough sketches of different ways to partition the product into modules

BBB and SBB are based on the building block system described by Borowski (1961). What is a big or small building block? The idea is that the design team would challenge themselves to determine what the module partitioning would be if the modules were big and therefore number of modules small and then again if there were many small modules in relation to the size of the product. For example, what would a LEGO wheel loader look like if it were made up of five large modules compared to 20 small modules? Here, designers have to take into account in particular that the number of interfaces to be managed increases with the number of modules required for the product. The architecture of the product can become confusing when the number of modules is large. Modules defined using BBB may have a high cost compared to SBB. For wheel loaders, BBBcompliant modules may include, for example, front carriage with boom attachment and front axle, rear carriage including motor and transmission, cabin and boom with bucket. SBB-compliant modules might include bucket, boom attachment module to front carriage, front carriage lower module and front axle and other modules. Thus, by following the SBB partitioning type, the module partitioning becomes wider.

BCE is based on the ideas of the universal chassis and the late point differentiation discussed in Section 3.1.2. When attaching module options to BCE, there should be no need to remove anything from it. BCE can be structured in such a way that it does not necessarily require that all the changing modules are attached to it alone. The modules may also be attached to each other. This means that the interface definitions must be made with other elements as well. In LEGO wheel loaders, such an BCE can be, for example, a combination of a front and rear carriage including engine, transmission, front and rear axles and supporting structures.

MCE follows descriptions about product platforms discussed in Section 3.1.3. MCE is a standardised element that fulfils several essential basic functions of the product. For example, in wheel loaders, the MCE may include functions such as transmitting the force from engine and transmission to rear axle and moving the boom.

FBE relates to frames of machines and plant units typically seen in process plants as presented in Section 3.1.4. However, such a LEGO wheel loader has not yet been made in teaching assignment. As the name suggest, product that uses FBE partitioning type should include a frame-like basic structure or structures to which modules are attached. Therefore, this base element is not equivalent to other modules. FBE is not interchangeable and no alternative base elements should be available for the same module system.

FE is a function-based way to divide a product into modules. This was already addressed in Sections 2 and 3.1.5. As in the case of FBE, not a single FE machine was made in the 2017 and 2018 MC assignments. 


\subsection{Effects of using identified partitioning types to support modularisation}

In 2019 course implementation, descriptions of partitioning types were used as a support material for modularisation assignment of LEGO wheel loaders. The largest change to the 2017 and 2018 implementations was that after assembling the basic wheel loader students had to select a partitioning type of the options described in the previous section before embarking on modular architecture design. Ten groups completed the MC in 2019. No one used SBB and FE in the 2019 MC. According to the students, partitioning of the wheel loader into small modules was avoided because the documentation of the interfaces scared and the benefits of this kind of partitioning were not directly seen because the exercise did not focus on production. Students also doubted that the final assembly using the modules would take more time compared to other partitioning types. The FE was avoided because during the assembly of basic wheel loader, the groups saw the complex placement of functions around the machine. The following subsections contribute to answering research question 2 .

\subsubsection{Big building blocks}

Two groups chose BBB partitioning type. One of these groups also considered BCE, but doubted that it would be able to meet the variation requirements well. The group Alpha thought that developing the $\mathrm{BBB}$ structure was more challenging than $\mathrm{BCE}$, but were motivated to try it. The other group Bravo that selected BBB argued that the logic behind the partitioning made with it seems clear when they had discussed all the options. Neither group followed their chosen partitioning type until the end. Groups found this too demanding on the wheel loader. The Alpha group eventually ended up using partitioning type, which is more like MCE. Variability was good, but the interfaces of modules were complex. The Bravo Group designed the machine eventually using BCE partitioning type. Their loader responded well to the need for variation and some of the modules were really convincing.

\subsubsection{Big common element}

Two groups, Charlie and Delta started to design a modular wheel loader based on the BCE partitioning type. The Charlie group's wheel loader was weak in its ability to meet the changing customisation demands. This is probably due to the large standardised element. The positive thing about the machine was the quick and easy assembly. Based on the 2017 and 2018 implementations, meeting customisation requirements using BCE partitioning type have been difficult. In 2019, in the BCE designed by the Delta group, modifications were successfully implemented with additional modules. The performance of the loader was excellent. Figure 4 presents examples of applying BCE partitioning type.

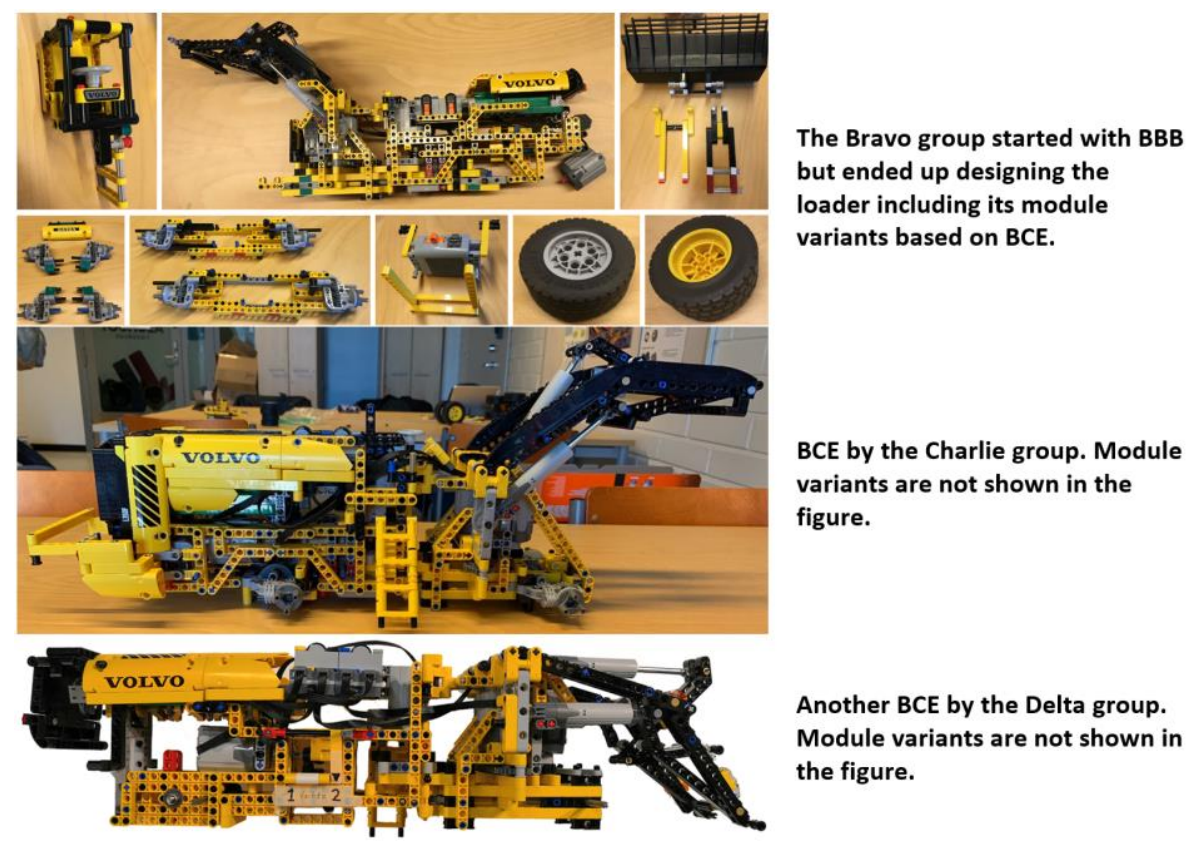

Figure 4. Results of BCE partitioning type 


\subsubsection{Multifunctional core element}

Five groups chose MCE. One of these groups, Echo, also considered BCE, but finally they decided that MCE seems to be a more interesting partitioning type to realise. Fulfilling customer requirements and following them on the Echo group machine was not flawless. The machine was not particularly fast and handling was not easy. The good thing was that the module variants were implemented with a small number of extra parts.

Second group, Foxtrot, considered the pros and cons of all the distribution methods. The group was skeptical about the benefits of the BBB because the amount of variation requirements could make it difficult to divide the product into big building blocks. They explained that SBB would probably be a viable option in terms of customisation, but the architecture could become complex. As a threat to $\mathrm{BCE}$, group considered it as difficult to implement the required product customisation. The FBE was doubted by them as being difficult to achieve the durability and functionality of the structures. They did not select the FE partitioning type, since the assembly of basic machine indicated that many functions are distributed around the machine. The machine implemented by Foxtrot followed the MCE partitioning type well and met customer requirements really well. In earlier years, this machine would have been one of the best, but in 2019, the standards were higher.

A third group Golf believed that this partitioning type would allow for an easy and clearly conceived modular system. They argumented that when there is enough functionality in the core element of the module, the structure of the modules can be simplified. The Golf group's machine performed best. In addition, they implemented both pneumatic and electromechanical booms with a small number of items. Fourth group, Hotel, stated that the most important functions for wheel loader operation can be standardised inside the core element (they discussed about transmission and chassis). They also thought that the modules containing the remaining functions can be connected to the core block using standardised interfaces. The work of the group Hotel followed the partitioning type of MCE very well. The assembly of the variant and test runs of the machine went smoothly and the wheel loader was one of the best of the year. Finally, the fifth group, India, considered MCE to be the most suitable for them. Their modular wheel loader met the requirements and passed the driving tests.

The MCE seems to be an easy approach to module partitioning, but it requires work to meet the customisation requirements and make a compact, well-functioning machine. However, it would seem a suitable approach for a LEGO wheel loader based on 2019 implementations. Figure 5 presents examples of applying the MCE partitioning type.

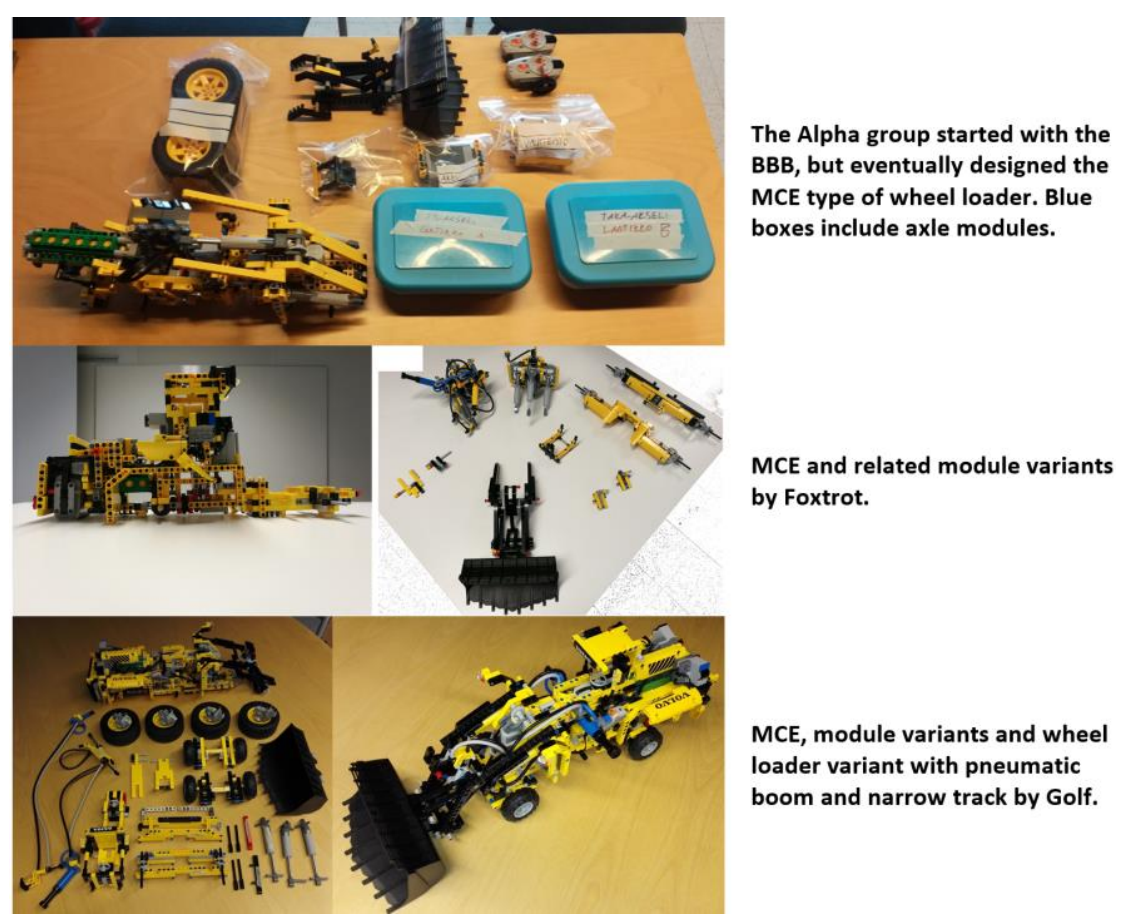

Figure 5. Results of MCE partitioning type 


\subsubsection{Frame-like base element}

One group, Juliett, chose FBE as the partitioning type to use. The group justified their choice by stating that they believe FBE makes the structure easy to modularise and allows them to meet the requirements set in the best way. They thought that the structure will become considerably lighter than the original, but at the same time it will require a lot of designing and rebuilding. The module variants designed around the frame met the customisation requirements well and the design also supports the development of new modular variants. The machine was challenging to assemble. FBE is shown in Figure 6.

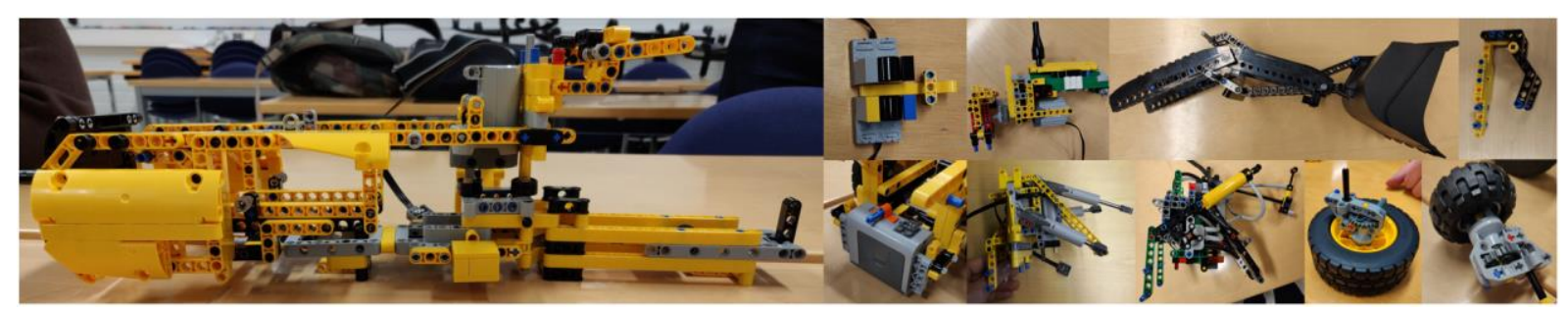

Figure 6. Wheel loader frame based on the FBE partitioning type and the module variants

\section{Conclusion}

Based on the literature and teaching experiments related to modularisation we studied what alternatives can be found in partitioning product into modules. We called these alternatives as partitioning types. We also investigated how descriptions of partitioning types supported modularisation in the teaching assignment where the majority of designers were novices (students). Ten group got to choose the partitioning type they follow. Although some repeating patterns were seen, such as the partitioning type of big building blocks turned out to be too challenging, the small sample size in terms of generalisability should be taken into account when analysing the results. One might also wonder if some group would have eventually come up with a less common solution like FBE discussed in Section 4.2.4 if the descriptions of different partitioning types would have not been available in the beginning of modularisation assignment? Thus, further research is needed to gain a stronger evidence of the differences in the different partitioning types, including their benefits and challenges.

In LEGO exercises, student groups chose one partitioning type but in industrial reality different sections of complex products may be based on different partitioning types. In the industry, it is difficult to arrange a modularisation project of this kind where the assignment is identical for many development teams. Nonetheless, the ultimate goal of future research is to find more support to industrial modularisation projects. The vision is that there would be simple yet informative guidelines that would facilitate different modularisation organisations in finding the most beneficial way to partition their products into modules.

\section{References}

Alstom (2008), Alstom unveils Prima II, its new modular locomotive platform, available at: https://www.alstom. com/press-releases-news/2008/5/Alstom-unveils-Prima-II-its-new-modular-locomotive-platform-20080520

Andreasen, M.M. (2011), “45 Years with design methodology”, Journal of Engineering Design, Vol. 22 No. 5 , pp. 293-332.

Borowski, K.-H. (1961), Das Baukastensystem in Der Technik, Springer-Verlag, Berlin Heidelberg.

Caterpillar (2015), The Rail Business of Wagner Asia Equipment LLC, available at: https://www.slideshare.net/ OtgontugsU/cat-repowered-locomotive

Deloitte Consulting GmbH (2017), Beyond the Noise: The Megatrends of Tomorrow's World, available at: https://www2.deloitte.com/content/dam/Deloitte/nl/Documents/public-sector/deloitte-nl-ps-megatrends2ndedition.pdf

Erixon, G. (1998), Modular Function Deployment - A Method for Product Modularisation, The Royal Institute of Technology, Stockholm, Sweden.

Förg, A. et al. (2014), "Enabling modularisation potentials by standardized vehicle layouts", In: Laakso, M. and Ekman, K. (Eds.), Proceedings of NordDesign 2014, The Design Society, Espoo, Finland, pp. 754-764.

Fujimoto, T. (2007), Competing to Be Really, Really Good - The behind-the-Scenes Drama of Capability Building Competition in the Automobile Industry, International House of Japan, Tokyo. 
Harlou, U. (2006), Developing Product Families Based on Architectures - Contribution to a Theory of Product Families, Technical University of Denmark.

Hauser, J.R. and Clausing, D. (1988), "The House of Quality", Harvard Business Review, No. May.

Juuti, T. (2008), Design Management of Products with Variability and Commonality - Contribution to the Design Science by Elaborating the Fit Needed between Product Structure, Design Process, Design Goals, and Design Organisation for Improved $R \& D$ Efficiency, Tampere University of Technology.

Juuti, T., Pakkanen, J. and Lehtonen, T. (2019), "Empirical Study of Good, Bad and Ugly Modular Engineering Solutions in Machinery Manufacturing Industry", Proceedings of the Design Society: International Conference on Engineering Design, Vol. 1, Cambridge University Press, pp. 2981-2990.

Kong, F.B. et al. (2009), "On Modular Products Development”, Concurrent Engineering, Vol. 17 No. 4, pp. 291-300.

Krause, D. and Eilmus, S. (2011), "A Methodological Approach for Developing Modular Product Families", Proceedings of International Conference on Engineering Design, ICED11, August 15-18, Technical University of Denmark, Copenhagen.

Kristjansson, A.H., Jensen, T. and Hildre, H.P. (2004), "The term platform in the context of a product developing company", In: Marjanovic, D. (Ed.), Proceedings of DESIGN 2004, the 8th International Design Conference, Dubrovnik, Croatia, pp. 325-330.

Lee, H.L. and Tang, C.S. (1997), "Modelling the Costs and Benefits of Delayed Product Differentiation", Management Science, INFORMS, Vol. 43 No. 1, pp. 40-53.

LEGO (2019), Remote-Controlled VOLVO L350F Wheel Loader, available at: https://www.lego.com/enfi/product/remote-controlled-volvo-1350f-wheel-loader-42030

Lehtonen, T. (2007), Designing Modular Product Architecture in the New Product Development, Tampere University of Technology, Tampere.

Lehtonen, T. et al. (2011), "Brownfield Process for developing of product families", ICED11: 18th International Conference on Engineering Design, Design Society, Copenhagen, p. 10.

Martin, M.V. and Ishii, K. (2002), "Design for variety: developing standardized and modularized product platform architectures", Research in Engineering Design, Springer-Verlag, Vol. 13 No. 4, pp. 213-235.

Nomaguchi, Y. et al. (2012), "Design Method Selection Matrix for Facilitating Product Platform and Family Design", Volume 5: 6th International Conference on Micro- and Nanosystems; 17th Design for Manufacturing and the Life Cycle Conference, ASME, p. 643.

Pahl, G. and Beitz, W. (2013), Engineering Design: A Systematic Approach, Vol. 11, Springer Science \& Business Media.

Pakkanen, J. (2015), Brownfield Process: A Method for the Rationalisation of Existing Product Variety towards a Modular Product Family, Tampere University of Technology.

Pakkanen, J., Juuti, T. and Lehtonen, T. (2016), "Brownfield Process: A method for modular product family development aiming for product configuration”, Design Studies, Elsevier Ltd, Vol. 45, pp. 210-241.

Pakkanen, J., Juuti, T. and Lehtonen, T. (2019), "Identifying and addressing challenges in the engineering design of modular systems - case studies in the manufacturing industry", Journal of Engineering Design, Vol. 30 No. 1, pp. 32-61.

Salvador, F. (2007), "Toward a Product System Modularity Construct: Literature Review and Reconceptualization", IEEE Transactions on Engineering Management, Vol. 54 No. 2, pp. 219-240.

Sanchez, R. (1999), "Modular Architectures in the Marketing Process", Journal of Marketing, Vol. 63, pp. $92-111$.

Sanderson, S. and Uzumeri, M. (1995), "Managing product families: The case of the Sony Walkman", Research Policy, North-Holland, Vol. 24 No. 5, pp. 761-782.

Siemens. (2019), Vectron, available at: https://new.siemens.com/global/en/products/mobility/rail-solutions/ rolling-stock/locomotives/vectron.html

Steward, D.V. (1981), "The design structure system: A method for managing the design of complex systems", IEEE Transactions on Engineering Management, Vol. EM-28 No. 3, pp. 71-74.

Ulrich, K.T. and Eppinger, S.D. (2008), Product Design and Development, McGraw-Hill, New York.

Umeda, Y., Nonomura, A. and Tomiyama, T. (2000), "Study on life-cycle design for the post mass production paradigm", AI EDAM, Cambridge University Press, Vol. 14 No. 02, pp. 149-161.

Winterkorn, M. and Pötsch, H.D. (2012), Volkswagen Golf VII: Launch of a new era, Sardinia.

Zacharias, N.A. and Yassine, A.A. (2008), "Optimal platform investment for product family design", Journal of Intelligent Manufacturing, Vol. 19 No. 2, pp. 131-148. 